\title{
AMBIENTE DE APRENDIZAGEM EM CASA E O DESENVOLVIMENTO COGNITIVO NA EDUCAÇÃO INFANTIL
}

\author{
Mariane Campelo Koslinski ${ }^{1}$ \\ Renata CorrêA Gomes² \\ Blenda Luize Chor Rodrigues 3 \\ Felipe Macedo de Andrade 4 \\ Tiago Lisboa Bartholo 5
}

\begin{abstract}
RESUMO: O artigo explora o potencial do conceito de Ambiente de Aprendizagem em Casa para compreender desigualdades educacionais no início da escolarização obrigatória no Brasil. Utiliza dados de um estudo longitudinal realizado entre 2017 e 2018 em uma amostra aleatória de 46 escolas e 2.716 crianças matriculadas na pré-escola de uma rede pública municipal. Os modelos de regressão linear e multinível estimados indicaram uma associação entre a medida de Ambiente de Aprendizagem em Casa e o desenvolvimento cognitivo no início da escolarização obrigatória (effect sizes de 0,229 a 0,308), bem como a aprendizagem das crianças durante a pré-escola (effect sizes de 0,123 a 0,152 ). Discute-se a relevância dos resultados para subsidiar políticas de apoio às famílias e projetar possíveis efeitos da pandemia nas desigualdades educacionais.
\end{abstract}

Palavras-chave: Ambiente de Aprendizagem em Casa. Educação infantil. Estudo longitudinal. Desigualdades socioeducacionais.

\section{HOME LEARNING ENVIRONMENT AND COGNITIVE DEVELOPMENT DURING EARLY CHILDHOOD EDUCATION}

\begin{abstract}
The paper explores the Home Learning Environment concept's potential to enhance understanding of educational inequalities at the beginning of compulsory schooling in Brazil. The data comes from a longitudinal study conducted from 2017 to 2018 in a random sample of 46 schools and approximately
\end{abstract}

O estudo longitudinal que resultou neste artigo contou com financiamento do Banco Interamericano de Desenvolvimento, da Fundação Carlos Chagas Filho de Amparo à Pesquisa do Estado do Rio de Janeiro, do Conselho Nacional de Desenvolvimento Científico e Tecnológico e do Instituto Alfa e Beto.

1.Universidade Federal do Rio de Janeiro - Centro de Filosofia e Ciências Humanas -Faculdade de Educação - Rio de Janeiro (RJ), Brasil.E-mail: mckoslinski@ufrj.com

2.Stanford University - Graduate School of Education - International Education Policy Analysis - Stanford (CA), Estados Unidos da América. E-mail: renatacgomes95@gmail.com

3.University of North Carolina at Greensboro - School of Health and Human Sciences - Human Development and Family Studies - Greensboro (NC), Estados Unidos da América. E-mail: bcrodri2@uncg.edu

4.Universidade Federal do Rio de Janeiro - Centro de Filosofia e Ciências Humanas - Colégio de Aplicação - Rio de Janeiro (RJ), Brasil. E-mail: felipema8@gmail.com

5.Universidade Federal do Rio de Janeiro - Centro de Filosofia e Ciências Humanas - Colégio de Aplicação - Rio de Janeiro (RJ), Brasil. E-mail: tiagobartholo@ufrj.com

Editora de Seção: Luana Costa Almeida 
2,700 children attending preschool in a public municipal system. The linear and multilevel regression models indicate that the Home Learning Environment measure is associated with cognitive development at the beginning of compulsory schooling (effect sizes from 0.229 to 0.308 ) and learning during preschool (effect sizes from 0.123 to 0.152 ). It discusses the relevance of the findings for policies to support families and project possible effects of the pandemic on educational inequalities.

Keywords: Home Learning Environment. Early childhood education. Longitudinal study. Socio-educational inequality.

\section{AMBIENTE DE APRENDIZAJE EN EL HOGAR Y DESAROLLO COGNITIVO EN EDUCACIÓN INFANTIL}

RESUMEN: El artículo explora el potencial del concepto de Ambiente de Aprendizaje em el Hogar para comprender las desigualdades educativas al inicio de la escolaridad obligatoria en Brasil. Utiliza datos de un estudio longitudinal realizado entre 2017 y 2018 em una muestra aleatoria de 46 escuelas y 2.716 niños matriculados em el preescolar de una red municipal pública. Los modelos de regresión linear y multinivel estimados indicaron una asociación entre la medición de Ambiente de Aprendizaje en el Hogar y el desarrollo cognitivo al comienzo de la escolaridad obligatoria (effect sizes de 0,229 a 0,308), así como el aprendizaje de los niños durante el preescolar (effect sizes de 0,123 a 0,152). Se discute la relevancia de los resultados para informar las políticas apoyo familiar y proyectar los posibles efectos de la pandemia sobre las desigualdades educativas.

Palabras-clave: Ambiente de Aprendizaje em el Hogar. Educación infantil. Estudio longitudinal. Desigualdades socioeducativas.

\section{Introdução}

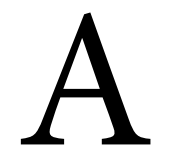

relação entre o nível socioeconômico (NSE) dos alunos e o sucesso escolar é amplamente estudada no campo da sociologia da educação. Por exemplo, o relatório Coleman, de 1966, já observava que a variação intraescolar era maior que a variação entre escolas, o que indicava maior peso da origem social no desempenho dos alunos em comparação com os fatores escolares considerados no estudo. Posteriormente, estudos em eficácia escolar - a partir de pesquisas com desenhos longitudinais e de medidas mais acuradas de NSE dos alunos -, mesmo identificando maior efeito das escolas, também observaram uma forte associação entre origem social e aprendizagem dos alunos (BROOKE; SOARES, 2008). Mesmo se tratando de um fenômeno universal, estudos indicam que a força da relação entre NSE e sucesso escolar apresenta grande variação entre países/sistemas educacionais e ao longo do tempo (CRAHAY; BAYE, 2013; SIRIN, 2005).

A relação entre o NSE dos alunos, bem como outros importantes marcadores sociais, e desempenho/ trajetória escolar também foi foco de diversos estudos desenvolvidos no contexto brasileiro (BONAMINO et al., 2010; FRANCO et al., 2007; SOARES, 2004). No entanto, a maioria desses estudos utiliza sistemas de avaliação externa, com desenhos transversais, e, portanto, não estima de forma adequada o impacto de tais variáveis sobre a aprendizagem dos alunos. Mesmo aqueles que utilizam dados longitudinais, como é o caso da pesquisa Estudo Longitudinal da Geração Escolar 2005 ou de estudos que utilizam sistemas de avaliação 
externa com desenho longitudinal, contam somente com medidas de linha de base referentes ao início da $1^{\text {a }}$ série/2 $2^{\circ}$ ano (BROOKE; BONAMINO, 2011) ou ao final de $1^{\circ}, 2^{\circ}$ ou $3^{\circ}$ anos do Ensino Fundamental (SOARES et al., 2017; CASTRO, 2016). O que nos leva à segunda lacuna nos estudos brasileiros: a quase total ausência de informações sobre as desigualdades ou o efeito da origem familiar sobre o desenvolvimento cognitivo das crianças no início da atual escolarização obrigatória. No Brasil, apesar da recente ampliação do acesso à educação infantil - e da expansão da obrigatoriedade para crianças de 4 e 5 anos -, esse nível de educação ainda permanece afastado das discussões sobre desigualdades educacionais (RODRIGUES; MUANIS, 2020; KOSLINSKI; BARTHOLO, 2019, 2020).

Por fim, estudos longitudinais, em especial desenvolvidos nos EUA e no Reino Unido, investigando crianças que frequentam a pré-escola e/ou no início da escolarização obrigatória, observaram, no desenvolvimento dessas crianças, desigualdades referentes não somente ao NSE, como também a processos internos das famílias; ou seja, oportunidades de aprendizagem que adultos propiciam para as crianças no contexto familiar (SYLVA et al., 2010; SAMMONS et al., 2008; RODRIGUEZ; TAMIS-LEMONDA, 2011). Novamente, poucos estudos no Brasil observam a associação de variáveis das interações das famílias com o desenvolvimento das crianças e mesmo os estudos existentes apresentam restrições por incluírem poucos casos e/ou não apresentarem desenhos longitudinais (ANDRADE et al., 2005; CACHAPUZ; HALPERN, 2006; FERREIRA; BARRERA, 2010).

Diante dessas lacunas, o presente artigo parte de uma bibliografia sobre o conceito de Home Learning Environment (HLE), aqui traduzido como Ambiente de Aprendizagem em Casa (AAC), e explora seu potencial para compreender desigualdades no desenvolvimento das crianças no início da escolarização obrigatória no contexto brasileiro. Para tanto, utiliza dados de um estudo longitudinal realizado entre 2017 e 2018, o qual compreendeu uma amostra aleatória de 46 escolas e 2.716 crianças de 4 a 5 anos que frequentavam a educação infantil da rede pública municipal de uma capital brasileira.

Para atingir o objetivo proposto, o artigo está dividido em quatro partes, além desta introdução e das considerações finais. A primeira parte discute o conceito de AAC e as evidências encontradas em estudos de larga escala sobre a sua relação com a aprendizagem de crianças na pré-escola e/ou no início da escolarização obrigatória. Em seguida, discutem-se estudos realizados no contexto brasileiro que focam em conceitos similares e buscam associá-los ao sucesso escolar. A segunda parte discute o desenho do estudo longitudinal que serviu de base para as análises realizadas neste artigo. $\mathrm{O}$ estudo envolve três ondas de coleta de dados de desenvolvimento cognitivo de crianças durante os dois anos da escolarização obrigatória, utilizando uma adaptação para o contexto brasileiro do instrumento Performance Indicators in Primary Schools (PIPS) (BARTHOLO et al., 2020a), além da aplicação de questionário para pais/responsáveis. A terceira parte do artigo apresenta o indicador de AAC elaborado a partir de itens desses questionários. Já a quarta parte apresenta análises bivariadas e multivariadas que utilizam o indicador de AAC como variável explicativa em regressões lineares, as quais estimam o desenvolvimento cognitivo das crianças no início da escolarização obrigatória e em regressões multinível, com modelos de valor agregado que, por sua vez, estimam a aprendizagem das crianças durante os dois anos da pré-escola. Em suas considerações finais, o artigo defende a importância da realização de estudos longitudinais de larga escala e do olhar para a relação entre AAC e o desenvolvimento das crianças na educação infantil. Argumenta-se que estudos aprofundados dessa relação podem gerar importantes evidências para informar políticas públicas com foco nas interações entre crianças e famílias e na relação família-escola. Além disso, no contexto de pandemia, esses estudos podem contribuir para a compreensão de mecanismos a partir dos quais o fechamento das escolas e as medidas de distanciamento social podem levar à ampliação das desigualdades educacionais. 


\section{Ambiente de Aprendizagem em Casa e Associação com Desenvolvimento das Crianças}

No Brasil, a Constituição de 1988 foi o primeiro documento legal a garantir o direito às crianças de 0 a 6 anos de serem atendidas em creches e pré-escolas. A partir da Lei de Diretrizes e Bases da Educação (1996), a educação infantil passou a ser definida como a primeira etapa da educação básica. Em 2009, a Emenda Constitucional n. 59 estendeu a educação obrigatória e gratuita dos 4 aos 17 anos e indicou que a universalização desse atendimento deveria ser concluída progressivamente até 2016. Assim, observam-se extensos esforços para a expansão da educação infantil em todo território nacional, tendo como consequência crianças iniciando sua trajetória escolar cada vez mais cedo. Ainda assim, para a maior parte das crianças brasileiras, a trajetória escolar começa aos 4 anos, uma vez que, mesmo com a expansão de vagas, em 2019, somente $37 \%$ das crianças de 0 a 3 , frequentavam creches/escolas (OPNE, s. d.).

Apesar dessa mudança, o segmento ainda permanece afastado da discussão sobre desigualdades na educação (RODRIGUES; MUANIS, 2020). Essa ausência é compreensível, em parte, porque, no contexto brasileiro, contamos com poucos estudos longitudinais ${ }^{1}$ e/ou desenhos mais robustos para explorar relações entre as desigualdades sociais e a aprendizagem, seja no início da escolarização obrigatória, seja durante a trajetória escolar dos alunos nos Ensinos Fundamental e Médio. Tal escassez é observada na educação infantil, com o agravante de que a obrigatoriedade da escolarização de crianças de 4 a 5 anos é muito recente (KOSLINSKI; BARTHOLO, 2020).

Em articulação com o debate sobre desigualdades educacionais na educação infantil, estudos têm observado que, na primeira infância, a família, como contexto mais imediato das crianças, exerce influência significativa sobre o que elas aprendem e seus pontos de partida. É nesse contexto que as crianças têm suas primeiras experiências de socialização e aprendizagem, as quais podem, por sua vez, ser ampliadas e potencializadas pela ação dos adultos que com elas convivem. Nessa direção, estudos recentes, realizados em diversos contextos/sistemas escolares a fim de compreender fatores escolares e extraescolares que influenciem o desenvolvimento e a trajetória escolar das crianças pequenas, para além de questões relacionadas à origem socioeconômica dessas, desenvolveram e têm utilizado o conceito de Home Learning Environment (HLE) ou Ambiente de Aprendizagem em Casa (AAC). Esse conceito reflete as oportunidades de aprendizagem que adultos propiciam para crianças no contexto familiar e é medido, geralmente, por meio do engajamento ativo em atividades de aprendizagem com as crianças, como: leitura de livros, brincadeira com números, pintura e desenho, ensino de músicas/poemas/rimas etc. (TAGGART et al., 2011; SYLVA et al., 2010; SAMMONS et al., 2008).

O AAC se refere à experiência que as crianças vivenciam no contexto de sua família e de sua comunidade, partindo do modelo bioecológico do desenvolvimento (BRONFENBRENNER; MORRIS, 2006). Tal modelo discute de que maneira ambientes como a família, a escola e a comunidade, bem como os processos vivenciados pelas crianças, associados às suas características pessoais, relacionam-se e influenciam o desenvolvimento delas ao longo do tempo. Nessa perspectiva, é nos primeiros anos de vida que a família exerce maior influência sobre o desenvolvimento das crianças, pois esse é o contexto mais imediato com o qual ela interage.

O indicador de AAC, nesse sentido, é uma medida diferente do NSE, porque está vinculado aos processos e interações entre responsáveis e crianças que ocorrem com regularidade na rotina familiar. Essa medida também se distancia do uso mais frequente do conceito de capital cultural de Pierre Bourdieu (1988) em estudos de estratificação educacional que focam na propriedade de objetos culturais valorizados, na participação em atividade da dita alta cultura ou na posse de certificados acadêmicos (NOGUEIRA, 2021). 
Portanto, no que tange ao campo da sociologia da educação, o AAC apresenta uma nova perspectiva, que diz respeito à existência e à frequência de processos e interações em que responsáveis e crianças se engajam na rotina familiar e que se relacionam com o desenvolvimento infantil.

O NSE está associado ao AAC e pode servir para explicar como determinadas condições de vida podem expandir ou limitar a capacidade dos responsáveis de promover ambientes enriquecedores ao desenvolvimento infantil. No entanto, o emprego de um indicador de AAC em pesquisas educacionais, mesmo com a introdução de controles de medidas estruturais, como renda, qualificação e ocupação dos responsáveis, tem auxiliado na explicação da variância da aprendizagem e da trajetória escolar das crianças, em especial em idade pré-escolar (SAMMONS et al., 2008; SYLVA et al., 2010). As pesquisas interessadas em mapear as interações entre pais e filhos, buscando entender como se relacionam ao desenvolvimento e ao desempenho das crianças na escola, indicam que o AAC, para além das medidas de NSE, ajuda a compreender as desigualdades no começo da trajetória escolar. Essas desigualdades se manifestam muito cedo e podem ser medidas desde a educação infantil (HOFF, 2006; MARTURANO, 2006; SYLVA et al., 2010; RODRIGUEZ; TAMIS-LEMONDA, 2011; ROWE, 2012).

Na Inglaterra, o estudo longitudinal Effective Provision of Pre-school and Primary Education (EPPE) seguiu aproximadamente 3 mil crianças, dos 3 aos 16 anos, buscando compreender o efeito da qualidade do atendimento na educação infantil sobre o desenvolvimento das crianças. Um dos focos do estudo foi analisar os efeitos do AAC no desenvolvimento das crianças em linguagem (literacy) e matemática (numeracy) (SYLVA et al., 2010; TAGGART et al., 2011; SAMMONS et al., 2008). Para tanto, foi utilizada uma escala a partir de itens que perguntavam a frequência (em escala de 0 a 7 ) com que pais/ responsáveis participavam de sete atividades com as crianças: leitura de livros; ida à biblioteca; brincadeira com números; pintura e desenho; ensino de letras; ensino de números; ensino de músicas/poemas/rimas. No início do estudo (medida inicial aos 3 anos de idade), as crianças foram avaliadas em compreensão verbal, vocabulário, análise de imagens e perguntas, utilizando blocos de construção. Foram avaliadas novamente aos 5 anos e, a partir dos 7 anos em diante, o desempenho cognitivo das crianças foi estimado a partir de testes padronizados nacionais.

Resultados do EPPE indicaram que um AAC mais elevado, medido aos 3 anos de idade, estava fortemente associado com maior desempenho cognitivo aos 5 anos de idade e seus efeitos eram mais fortes do que renda, NSE e/ou educação dos responsáveis. Controlando por características demográficas das crianças e NSE da família, o estudo observou um tamanho do efeito de 0,42 em matemática e de 0,69 em linguagem para crianças que experimentaram altos níveis de AAC quando comparadas com aquelas que experimentaram baixos níveis. Além disso, essa investigação identificou um efeito positivo e significativo do AAC sobre autorregulação, comportamento pró-social e hiperatividade aos 11 anos (SAMMONS et al., 2015).

Análises apresentadas em Melhuish et al. (2008) utilizando modelos de regressão multinomial encontraram resultados convergentes: crianças com maior AAC apresentavam, aos 5 anos de idade, maior probabilidade de possuírem resultados acima do esperado; crianças com menor AAC apresentavam maior probabilidade de resultados abaixo do esperado. Aos 7 anos de idade ( $3^{\circ}$ ano da escola primária), a influência do AAC, medido quatro anos antes, aparentava ser menor: estava associada somente à probabilidade de a criança estar no grupo de performance abaixo do esperado em comparação com o grupo de desempenho esperado (MELHUISH et al., 2008). Os autores desse estudo apresentam algumas hipóteses para essa menor associação: menor precisão da medida de desenvolvimento cognitivo utilizada aos 7 anos; menor importância das experiências familiares; e novas fontes de influência, como as escolares, que passariam afetar o desenvolvimento das crianças. Além disso, os autores advertem que os efeitos do AAC sobre o 
desenvolvimento das crianças aos 7 anos observados nas análises podem expressar não somente efeitos de longo prazo de experiências anteriores (na entrada da pré-escola), como também efeitos atuais do AAC.

$\mathrm{Na}$ mesma direção, uma importante pesquisa realizada no contexto norte-americano sobre prevenção de dificuldades em leitura, pesquisa essa que utiliza um conceito que se aproxima ao AAC, identificou que as diferenças no "ambiente de letramento" do contexto familiar da criança se relacionam com as diferenças no desempenho em leitura posteriores (SNOW; BURNS; GRIFFIN, 1998). Destaca-se, também, a importância específica da leitura com as crianças e da existência de materiais de leitura em casa para o crescimento em linguagem e o processo de pré-alfabetização (RODRIGUEZ; TAMIS-LEMONDA, 2011).

O trabalho de Rodriguez e Tamis-LeMonda (2011) analisou padrões de trajetória de AAC ao longo do tempo. O estudo seguiu 1.852 famílias e realizou medições do AAC quando as crianças tinham 15, 25, 37 e 63 meses de idade. Para criar o indicador de AAC (com intervalo de 0 a 6), foram coletadas, por meio de visitas às casas das famílias, informações sobre: atividades que os pais fazem com seus filhos; materiais adequados disponíveis (como tipos específicos de brinquedos para cada faixa etária); e qualidade das interações com a criança. Essas medidas foram agrupadas em seis padrões de trajetórias de AAC, alguns dos quais eram consistentemente baixos, alguns consistentemente altos e outros se caracterizavam por oscilações, sendo considerados moderados. Essa investigação também mediu o ponto de partida das crianças com relação aos desempenhos cognitivo e de linguagem.

Os resultados indicaram que os padrões de trajetória de AAC estão relacionados às características sociodemográficas das famílias e às habilidades das crianças em vocabulário e letramento. As análises mostram que $70 \%$ das crianças cujas famílias possuem um padrão de trajetória alta e consistente de AAC obtiveram desempenho esperado ou acima do esperado, de acordo com as normas nacionais norte-americanas, enquanto somente $7 \%$ das crianças que estão no grupo de trajetória baixa e ascendente atingiram esses mesmos resultados. As diferenças entre esses ambientes sugerem uma diversidade de ponto de partida em relação ao conhecimento e às habilidades das crianças ao longo da pré-escola. A pesquisa também revelou que, quando as crianças têm 15 e 25 meses, o AAC está mais associado às habilidades de linguagem receptiva, enquanto, quando estão mais velhas, relaciona-se à capacidade de identificar letras e palavras. Isso alerta para o fato de que os ambientes "consistentes" são aqueles que continuam apoiando o desenvolvimento das crianças ao longo do tempo, na medida em que correspondem às necessidades que emergem a cada fase de desenvolvimento.

No contexto brasileiro, o campo da educação se debruçou pouco sobre o impacto do ambiente de aprendizagem proporcionado pelos adultos de referência das crianças sobre seu desenvolvimento na educação infantil. ${ }^{2}$ Pesquisas sobre a relação família-escola geralmente discutem a comunicação entre esses dois mundos, a participação dos responsáveis na vida escolar das crianças e os papéis da educação infantil e da família (RODRIGUES; MUANIS, 2020). Os estudos brasileiros sobre a relação entre o ambiente familiar da criança e seu desenvolvimento escolar, em geral, são da área da saúde e não possuem instrumentos específicos que tenham um foco para o AAC de crianças na primeira infância.

Por exemplo, um estudo que utilizou desenho transversal verificou uma associação entre as crianças que usufruem de melhor qualidade da estimulação no ambiente doméstico e o desenvolvimento infantil (ANDRADE et al., 2005). A amostra contou com 350 crianças entre 17 e 42 meses e utilizou o inventário Home Observation for Measurement of the Environment Scale (HOME) para mensurar a estimulação no ambiente familiar. 
$\mathrm{Na}$ busca de investigar associações entre fatores ambientais e a prevalência de suspeita de atraso de linguagem em crianças de até 6 anos de idade, Cachapuz e Halpern (2006) aplicaram um questionário para as mães das crianças. Esse contemplava, entre uma série de questões, os estímulos familiares em casa e apresentou como resultado que as crianças pouco estimuladas com leituras, conversas e interação em casa têm uma probabilidade 2,88 vezes maior de terem um teste suspeito para atraso de linguagem.

Em virtude da escassez de estudos de bom custo-benefício e adequados para compreender o ambiente familiar, Marturano (2006) propôs o Inventário de Recursos do Ambiente Familiar (RAF) ${ }^{3}$. Em estudos que utilizam o inventário, os itens que mais se relacionaram com o desempenho foram: "o acesso a passeios, a disponibilidade de livros e brinquedos e as oportunidades de interação com os pais em casa" (MARTURANO, 2006). A pesquisa de Ferreira e Barrera (2010), realizada com uma turma de trinta crianças entre 5 e 6 anos, utilizou esse instrumento e encontrou que a presença de jornais, revistas, livros e brinquedos, assim como as atividades compartilhadas com os pais, incluindo reuniões familiares, mostrou-se associada ao que as crianças sabem sobre leitura e escrita. Outra pesquisa investigou setenta crianças no processo de transição da educação infantil para o $1^{\circ}$ ano do Ensino Fundamental. Os resultados indicaram que a consciência fonológica da criança, somada aos recursos do ambiente familiar ${ }^{4}$ e às práticas parentais positivas, é precursora de competência na transição para o $1^{\circ}$ ano do Ensino Fundamental (MARTURANO; TRIVELLATO-FERREIRA, 2008).

De uma forma geral, os resultados apresentados nas pesquisas brasileiras apontam associações significativas entre o ambiente familiar e o desenvolvimento das crianças. Os estudos buscam mensurar o ambiente familiar geral, o que resulta em uma medida bem ampla e que engloba uma série de outros fatores (socioeconômicos, de saúde, relativos à gestação, de posse de bens etc.), diferindo-se de uma medida de AAC com foco maior no ambiente de aprendizagem em casa. Vale ressaltar que, embora o ambiente familiar tenha sido mensurado de diversas formas nos estudos brasileiros, os itens relativos às interações adulto-criança e às práticas parentais estimulantes sempre apareciam associados ao desenvolvimento. Além disso, é relevante destacar que nenhum dos estudos brasileiros mencionados apresentava simultaneamente as seguintes características: ser longitudinal, ter uma amostra de largaescala e ter como foco crianças na educação infantil.

\section{Desenho do Estudo, Amostra, Coleta de Dados e Análises}

O presente trabalho utilizou dados de um estudo longitudinal que coletou dados entre março de 2017 e dezembro de 2018 com crianças matriculadas em escolas da rede pública de uma capital brasileira. O objetivo do estudo foi obter uma medida de "linha de base" e acompanhar as mesmas crianças durante a pré-escola, ${ }^{5}$ visando compreender aspectos contextuais escolares e extraescolares associados ao desenvolvimento das crianças. Este artigo utiliza os dados coletados na pesquisa em questão e tem como objetivo principal discutir a relação entre o AAC proporcionado pelas famílias e o desenvolvimento das crianças tanto na entrada na pré-escola quanto durante esse período da educação.

A pesquisa selecionou uma amostra probabilística aleatória de 46 escolas e aproximadamente 2.700 crianças de uma rede municipal, estratificadas por área e por tipo de oferta escolar. O estudo longitudinal contou com três ondas de coleta de dados sobre as crianças: duas coletas em 2017, no início e fim do ano letivo, aos 4/5 anos de idade; e uma coleta no fim do ano letivo de 2018, aos 5/6 anos. ${ }^{6}$ 
A Fig. 1 a seguir ilustra o desenho do estudo longitudinal:

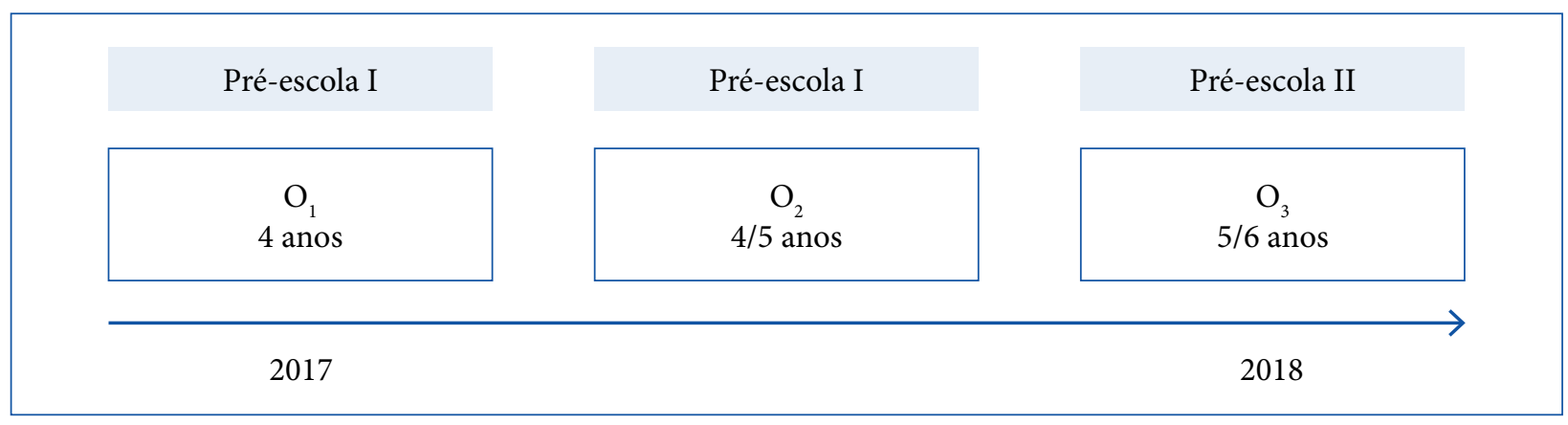

Fonte: Elaboração própria.

Figura 1. Desenho do estudo longitudinal

Nas ondas 2 e 3, foram incluídas na amostra crianças que entraram durante a pré-escola nas escolas da amostra. Para minimizar a mortalidade amostral, o estudo também buscou acompanhar as crianças que, no seu decorrer, migraram para outras escolas da rede pública municipal. Dessa forma, o número de crianças que participaram do estudo longitudinal aumentou de 2.716 na onda 1 para 2.848 e 3.552 nas ondas 2 e 3 , respectivamente.

Em cada onda do estudo, foram coletados dados sobre o desenvolvimento cognitivo das crianças, com relação à coordenação motora fina e global. A coleta de dados cognitivos utilizou uma adaptação do instrumento PIPS, uma ferramenta testada e utilizada por vinte anos no Reino Unido e em outros países, a qual foi desenvolvida por pesquisadores da Durham University, na Inglaterra (TYMMS, 1999). O instrumento foi traduzido e adaptado para o contexto brasileiro e, em seguida, foi realizado um pré-teste com 560 crianças em três cidades (BARTHOLO et al., 2020a). O instrumento mede duas dimensões - linguagem e matemática -, sendo elas compostas pelas seguintes subdimensões: a) escrita; b) vocabulário; c) ideias sobre leitura - avalia conceitos sobre diferentes impressos; c) consciência fonológica; d) identificação de letras; e) reconhecimento de palavras e leitura; f) ideias sobre matemática; g) contagem e números; h) adição e subtração sem símbolos; i) identificação de formas; j) identificação de números. Os escores de linguagem e matemática foram estimados a partir dos itens do teste cognitivo da adaptação do teste PIPS utilizando medidas de Rasch (BOONE, 2016), a partir do software Winsteps.

Além dos dados cognitivos das crianças, o estudo longitudinal coletou informações do contexto familiar durante as ondas 2 e 3, a partir de questionários para pais e responsáveis. Os dados demográficos das crianças (idade, cor e sexo) e a complementação de dados sobre o contexto socioeconômico da família (escolaridade dos pais e participação do programa bolsa-família) foram obtidos a partir do Sistema de Gestão Acadêmica da Secretaria Municipal de Educação (SGA/SME).

A Tabela 1 apresenta a quantidade de casos de crianças avaliadas na primeira onda e avaliadas em duas ou mais ondas que também contam com informações provenientes dos questionários contextuais:

Tabela 1. Número total de crianças avaliadas na onda 1, em duas ou mais ondas e com questionário contextual

\begin{tabular}{ccccc} 
& Onda 1 & Ondas 1 e 2 & Ondas 2 e 3 & Ondas 1, 2 e 3 \\
\hline Cognitivo & 2.716 & 2.261 & 2.331 & 1.935 \\
\hline Cognitivo + contextual & 1.722 & 1.718 & 1.841 & 1.550 \\
\hline
\end{tabular}

Fonte: Elaboração própria. 
As análises incluíram regressões lineares para estimar a associação entre AAC e o desenvolvimento cognitivo no início da pré-escola, utilizando a base de dados de crianças que realizaram a onda 1 do teste cognitivo e de cujos pais/responsáveis obtivemos questionários (1.722 casos). Modelos de regressão multinível lineares foram estimados para observar o efeito do AAC sobre a aprendizagem das crianças durante a pré-escola. Para minimizar os dados faltantes, utilizamos os bancos com crianças avaliadas nas ondas 1 e 2 ( 1.718 casos) e nas ondas 2 e 3 (1.841 casos) com respostas para os questionários do pais/responsáveis.

\section{Medida do Ambiente de Aprendizagem em Casa}

O questionário com os responsáveis versava sobre vários aspectos do contexto da criança e de sua família, incluindo questões sobre escolaridade dos pais/responsáveis, renda, posse de bens, participação em programas de transferência de renda, assim como características da criança e do cotidiano familiar, como número de faltas, nascimento prematuro, existência de livros na casa etc. A aplicação do questionário com os responsáveis aconteceu nos horários de entrada e saída das crianças, buscando assim influenciar menos na rotina escolar e reduzir o tempo necessário com os responsáveis das crianças.

Para a composição do indicador de AAC, utilizamos as respostas dos responsáveis sobre duas dimensões. A primeira teve como ponto de partida a adaptação de questões utilizadas no estudo EPPE (SYLVA et al., 2010; SAMMONS, 2008). Os itens do questionário de pais/responsáveis indagavam se uma pessoa maior de 15 anos havia participado, com as crianças, na semana anterior ao estudo, das seguintes atividades: 1) ler livros ou olhar para figuras; 2) cantar músicas; 3 ) desenhar, pintar ou recortar; 4) brincar com letras ou alfabeto; 5) contar objetos ou brincar com números; 6) brincar com cores e/ou formas geométricas. ${ }^{7}$ Além disso, o indicador considerou se a família possuía livros e jogos infantis e se havia mais de dez livros (de qualquer tipo) na casa da criança. Essas duas últimas questões tratam de uma dimensão mais "estrutural" do conceito e se aproximam das medidas relacionadas à dimensão de posse de materiais adequados à faixa etária utilizadas no estudo de Rodriguez e TamisLeMonda (2011). As questões foram incluídas na medida de AAC por seu potencial de indicar um investimento da família em relação à educação, além de não se vincularem diretamente à renda da família, como outros bens (carro, máquina de lavar roupa, computador etc.). A partir dos itens acima descritos, o indicador de AAC foi elaborado utilizando o modelo de Rasch, por meio do software Winsteps. Esse procedimento possibilitou a análise teórica e empírica de cada item componente do indicador.

O teste de unidimensionalidade foi realizado com os itens que compõem o indicador para verificar se mediam apenas um construto (traço latente). O teste para verificar a variância não explicada dos itens não deve apresentar valores maiores que dois eigenvalues para garantir a unidimensionalidade do indicador. O resultado do teste indicou que os itens não possuíam valores maiores que dois eigenvalues e, portanto, não captavam mais de uma dimensão. Para mais detalhes, ver Linacre (2020.

A Tabela 2 a seguir apresenta a frequência das respostas aos itens que compuseram o indicador de AAC e a Fig. 2 apresenta a distribuição dos itens e das crianças no mapa de Wright: 
Tabela 2. Frequência nas respostas para cada item do indicador de $\mathrm{AAC}^{8}$

\begin{tabular}{cll}
\hline Itens & Sim & Não \\
\hline Tem livros infantis & 86,2 & 13,0 \\
\hline Tem jogos infantis & 68,5 & 30,8 \\
\hline Leu livros ou olhou figuras & 72,0 & 28,0 \\
\hline Cantou músicas & 82,9 & 17,1 \\
\hline Desenhou, pintou ou recortou & 80,1 & 19,9 \\
\hline Brincou com letras ou alfabeto & 69,8 & 30,2 \\
\hline Contou objetos ou brincou com números & 68,3 & 31,7 \\
\hline Brincou com cores e/ou formas geométricas & 64,1 & 35,9 \\
\hline Tem mais de dez livros & 47,7 & 57,1 \\
\hline
\end{tabular}

Fonte: Elaboração própria.

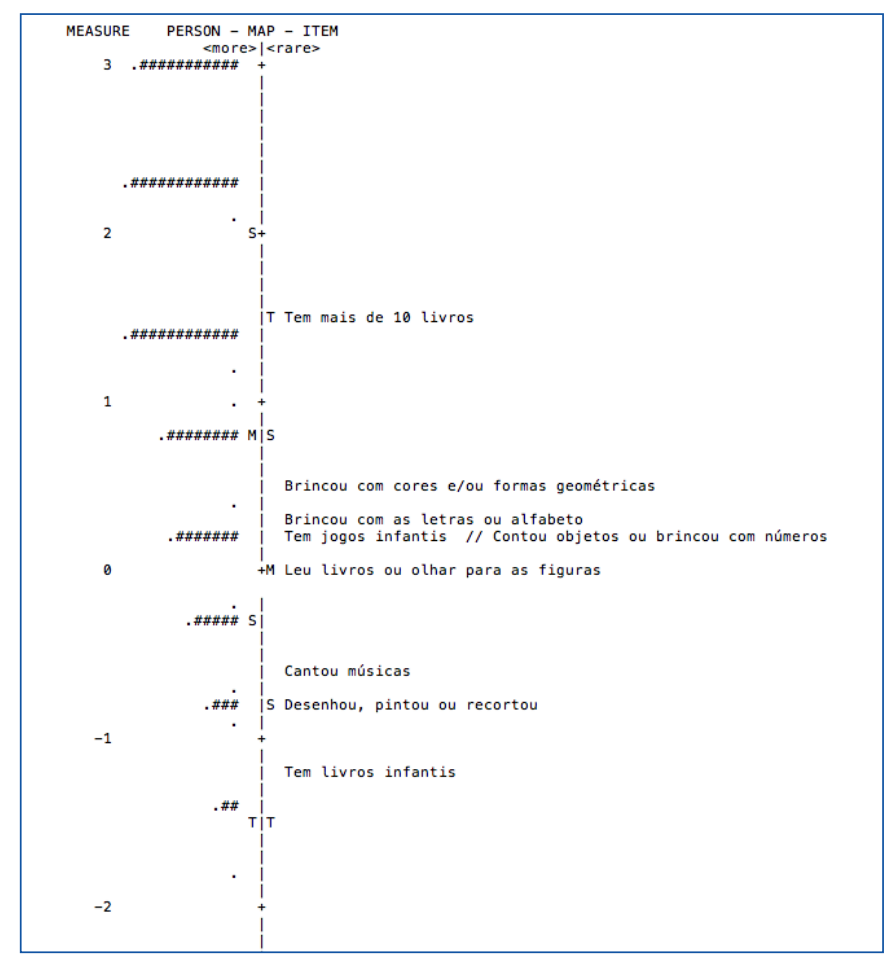

Fonte: Elaboração própria.

Figura 2. Mapa de Wright para os itens que compõem o indicador de AAC

A Tabela 2 indica que as respostas mais comuns foram que a família possua livros infantis e que adultos tenham desenhado, pintado, recortado e/ou cantado músicas com as crianças na semana anterior. As respostas menos frequentes entre os responsáveis foram possuir mais de dez livros em casa e brincar com as crianças com cores e/ou formas geométricas, assim como com letras ou alfabeto.

Já na Fig. 2, observamos o mapa de Wright que plota os itens do instrumento de acordo com sua ordem de dificuldade: os itens são apresentados dos mais fáceis (parte inferior) para os mais difíceis (parte superior do mapa) ou, no caso do indicador de AAC, das atividades mais frequentes até as menos frequentes. Do lado esquerdo do mapa, o símbolo \# é usado para representar os indivíduos que foram expostos ao teste, cada \# representa quarenta crianças (BOONE, 2016). O mapa confirma uma progressão teórica em relação aos itens, na medida em que atividades mais ligadas ao "mundo escolar", como brincar com formas geométricas, letras ou alfabeto e números, são menos frequentes 
do que desenhar, pintar, recortar e cantar músicas. É importante notar que ter livros infantis é um pré-requisito para a leitura com as crianças e uma grande proporção das famílias indicou que não tem mais de dez livros. Um número menor de familiares reportou a leitura ou brincadeiras com letras no cotidiano da família.

Algumas limitações importantes se apresentam a partir do mapa de itens, como a alta frequência de respostas positivas à realização de atividades com as crianças. Pelo fato de a medida ser indireta, torna-se impossível saber se de fato essas atividades ocorreram, bem como o tempo de duração e as características mais qualitativas das atividades desenvolvidas. Como consequência, o indicador de AAC discrimina pouco as crianças que possuem uma medida de ambiente de aprendizagem mais alta.

\section{Análises e Resultados}

A Tabela 3 apresenta a descrição das variáveis utilizadas nas análises e as fontes de dados utilizadas e a Tabela 4 mostra as estatísticas descritivas das variáveis do estudo.

Tabela 3. Descrição das variáveis analisadas e suas fontes de dados

\begin{tabular}{|c|c|c|c|}
\hline \multirow{2}{*}{ Nome } & \multirow{2}{*}{ Tipo } & Descrição & \multirow{2}{*}{ Fonte } \\
\hline & & Variáveis Dependentes & \\
\hline Linguagem & Contínua & Medida de linguagem nas ondas 1,2 ou 3 & Teste cognitivo \\
\hline \multirow[t]{3}{*}{ Matemática } & Contínua & Medida de matemática nas ondas 1,2 ou 3 & Teste cognitivo \\
\hline & & Variáveis Explicativas & \\
\hline & & Nível 2 - escola & \\
\hline $\begin{array}{l}\text { Baixa escolaridade } \\
\text { pais } \\
\text { (prop. escola) }\end{array}$ & Contínua & $\begin{array}{c}\text { Proporção de crianças cujos pais não possuem } \\
\text { Ensino Médio ou Superior }\end{array}$ & $\begin{array}{l}\text { Quest. responsáveis e } \\
\text { SGA/SME }\end{array}$ \\
\hline $\begin{array}{c}\text { Cor } \\
\text { (prop. negros escola) }\end{array}$ & Contínua & Proporção de crianças negras & SGA/SME \\
\hline \multirow[t]{2}{*}{$\begin{array}{c}\text { Pobreza } \\
\text { (prop. escola) }\end{array}$} & Contínua & $\begin{array}{c}\text { Proporção de crianças cujos pais participam do } \\
\text { programa bolsa-família }\end{array}$ & $\begin{array}{l}\text { Quest. responsáveis e } \\
\text { SGA/SME }\end{array}$ \\
\hline & & Nível 1 - criança & \\
\hline Linguagem & Contínua & Medida de linguagem nas ondas 2 ou 3 & Teste cognitivo \\
\hline Matemática & Contínua & Medida de matemática nas ondas 2 ou 3 & Teste cognitivo \\
\hline Indicador de AAC & Contínua & Indicador de ambiente de aprendizagem em casa & Quest. responsáveis \\
\hline Baixa escolaridade & Dicotômica & $\begin{array}{l}\text { Indica se pais/responsáveis da criança não } \\
\text { concluíram Ensino Médio } \\
(0=\operatorname{Sim} ; 1=\text { Não })\end{array}$ & $\begin{array}{l}\text { SME e quest. } \\
\text { responsáveis }\end{array}$ \\
\hline Pobreza & Dicotômica & $\begin{array}{l}\text { Indica se responsáveis são beneficiários de } \\
\text { programas de transferência de renda } \\
(0=\text { Não; } 1=\text { Sim })\end{array}$ & $\begin{array}{l}\text { SGA/SME e quest. } \\
\text { responsáveis }\end{array}$ \\
\hline Sexo & Dicotômica & $\begin{array}{l}\text { Indica o sexo da criança } \\
(0=\text { Menina; } 1=\text { Menino })\end{array}$ & SGA/SME \\
\hline Não branco & Dicotômica & $\begin{array}{c}\text { Indica a cor da criança } \\
\text { (declarada pelos pais/responsáveis) } \\
(0=\text { Branco; } 1 \text { = Não branco })\end{array}$ & SGA/SME \\
\hline Idade & Contínua & Indica a idade em anos nas ondas 1,2 ou 3 & SGA/SME \\
\hline
\end{tabular}

Fonte: Elaboração própria. 
Tabela 4. Estatísticas descritivas das variáveis utilizadas nas análises

\begin{tabular}{ccc}
\hline Variáveis & Média & DP \\
\hline Linguagem (onda 1) & $-0,27$ & 0,95 \\
\hline Linguagem (onda 2) & 0,27 & 0,88 \\
\hline Linguagem (onda 3) & 0,93 & 0,95 \\
\hline Matemática (onda 1) & $-2,77$ & 1,32 \\
\hline Matemática (onda 2) & $-1,82$ & 1,38 \\
\hline Matemática (onda 3) & $-0,62$ & 1,55 \\
\hline Baixa escolaridade pais (prop. escola) & 0,46 & 0,13 \\
\hline Cor (prop. negros escola) & 0,63 & 0,11 \\
\hline Pobreza (prop. escola) & 0,30 & 0,09 \\
\hline Indicador de AAC & 1,32 & 1,49 \\
\hline Baixa escolaridade & 0,47 & - \\
\hline Pobreza & 0,43 & - \\
\hline Sexo & 0,52 & - \\
\hline Não branco & 0,62 & - \\
\hline Necessidades especiais & 0,03 & 0,35 \\
\hline Idade (onda 1) & 4,39 & 0,35 \\
\hline Idade (onda 2) & 5,06 & \\
\hline
\end{tabular}

Fonte: Elaboração própria.

A Tabela 5 apresenta a correlação de Pearson entre o indicador de AAC e as medidas de linguagem e matemática das crianças nas ondas 1 (início da pré-escola), 2 (fim do primeiro ano da pré-escola) e 3 (fim do segundo ano da pré-escola).

Tabela 5. Correlação de Pearson (r) entre medidas de linguagem e matemática (ondas 1, 2 e 3) e ambiente de aprendizagem em casa (AAC)

\begin{tabular}{ccc}
\hline Medida & AAC & N \\
\hline Linguagem $($ onda 1) & $0,192^{\star * *}$ & 1699 \\
\hline Linguagem $($ onda 2) & $0,208^{\star * *}$ & 1930 \\
\hline Linguagem $($ onda 3) & $0,222^{\star * *}$ & 2271 \\
\hline Matemática (onda 1) & $0,182^{* * *}$ & 1699 \\
\hline Matemática (onda 2) & $0,220^{* * *}$ & 1930 \\
\hline Matemática (onda 3) & $0,202^{\star * *}$ & 2271 \\
\hline
\end{tabular}

Nota: ${ }^{* *} \mathrm{p}<0,001 ;{ }^{* *} \mathrm{p}<0,01 ;{ }^{*} \mathrm{p}<0,05$; Fonte: Elaboração própria.

Observamos uma correlação moderada entre as medidas de matemática e linguagem e o AAC, que variam de 0,182 e $0,222 .{ }^{9}$ As correlações entre AAC e as medidas cognitivas nas ondas 2 e 3 parecem mais fortes do que as correlações com a linha de base (medidas no início da pré-escola), o que sugere uma correlação do AAC não somente com o ponto de partida, mas também com a aprendizagem durante a pré-escola.

Em seguida, utilizamos modelos de regressão linear (Tabela 6) para estimar o desenvolvimento das crianças em linguagem e matemática no início da pré-escola (medidas da onda 1), utilizando variáveis explicativas de AAC (variável de interesse), bem como variáveis de controle (escolaridade dos responsáveis, pobreza, sexo e idade das crianças). As Tabelas 6, 7, 8 apresentam os coeficientes das regressões e seus 
respectivos intervalos de confiança e as Tabelas 9, 10 e 11, no "Anexo", indicam o tamanho do efeito (effect size) das variáveis explicativas estimadas a partir dos coeficientes obtidos nos modelos de regressão.

Effect sizes são formas simples de relatar diferenças entre dois grupos, em vez de simplesmente discutir a significância estatística (HATTIE, 2009; HIGGINS, KOKOTSAKY, COE, 2014). No presente trabalho, calculamos os efeitos de acordo com a metodologia desenvolvida por Tymms (2004). Dessa forma, as variáveis independentes contínuas foram padronizadas e os coeficientes reportados em effect sizes expressam as diferenças estimadas para indivíduos com um desvio-padrão acima e um desvio padrão abaixo da média. Para facilitar a interpretação dos resultados, utilizamos a classificação presente em Higgins, Kokotsaky e Coe (2014): 1) effect sizes até 0,18 são considerados pequenos; 2 ) de 0,19 até 0,44 moderados; 3 ) effect sizes de 0,45 a 0,69 são altos; e 4) effect sizes maiores que 0,70 são muito altos. ${ }^{10}$

Tabela 6. Modelos de regressão linear estimando linguagem e matemática na entrada da pré-escola

\begin{tabular}{|c|c|c|c|c|}
\hline & \multicolumn{2}{|c|}{ Linguagem } & \multicolumn{2}{|c|}{ Matemática } \\
\hline & Modelo 1 & Modelo 2 & Modelo 1 & Modelo 2 \\
\hline $\mathrm{AAC}$ & $\begin{array}{c}0,194^{* * *} \\
(0,147-0,240)\end{array}$ & $\begin{array}{c}0,143^{* * *} \\
(0,095-0,192)\end{array}$ & $\begin{array}{c}0,182^{* * *} \\
(0,136-0,229)\end{array}$ & $\begin{array}{c}0,103^{* * *} \\
(0,056-0,150)\end{array}$ \\
\hline Idade & & $\begin{array}{c}0,322^{* * *} \\
(0,270-0,374) \\
\end{array}$ & & $\begin{array}{c}0,321^{* * *} \\
(0,271-0,371) \\
\end{array}$ \\
\hline Sexo (menino) & & $\begin{array}{c}-0,202^{\star *} \\
(-0,294--0,110)\end{array}$ & & $\begin{array}{c}-0,034 \\
(-0,123-0,056)\end{array}$ \\
\hline Cor (negra) & & $\begin{array}{c}-0,092+ \\
(-0,187-0,002)\end{array}$ & & $\begin{array}{c}-0,157^{* * *} \\
(-0,249--0,65)\end{array}$ \\
\hline Baixa escolaridade & & $\begin{array}{c}-0,268^{* * *} \\
(-0,366--0,171)\end{array}$ & & $\begin{array}{c}-0,424^{\star * \star} \\
(-0,519--0,329)\end{array}$ \\
\hline Pobreza & & $\begin{array}{c}-0,121^{*} \\
(-0,217--0,024)\end{array}$ & & $\begin{array}{c}-0,156^{* * *} \\
(-0,250--0,062)\end{array}$ \\
\hline Constante & $\begin{array}{c}-0,008 \\
(-0,54-0,039)\end{array}$ & $\begin{array}{c}0,308 \\
(0,207-0,409)\end{array}$ & $\begin{array}{c}-0,006 \\
(-0,053-0,040)\end{array}$ & $\begin{array}{c}0,349 \\
(0,251-0,447)\end{array}$ \\
\hline $\mathrm{N}$ & 1698 & 1590 & 1698 & 1590 \\
\hline $\mathrm{R} 2$ & 0,037 & 0,151 & 0,033 & 0,172 \\
\hline
\end{tabular}

Notas: ${ }^{* *} \mathrm{p}<0,001 ;{ }^{* *} \mathrm{p}<0,01 ;{ }^{*} \mathrm{p}<0,05 ;+\mathrm{p}<0,10$. A tabela apresenta os coeficientes e os intervalos de confiança estimados; Fonte: Elaboração própria.

Os coeficientes para o AAC são estatisticamente significativos nos quatro modelos estimados, mostrando a relação do indicador com o desenvolvimento cognitivo das crianças no começo da educação compulsória. O tamanho do efeito para o AAC é moderado para linguagem (effect size de 0,308) no modelo que inclui variáveis de controle como escolaridade dos pais/responsáveis, pobreza, cor, sexo e idade das crianças (modelo 2). No modelo que estima a medida de matemática na entrada da pré-escola, após a inserção das variáveis de controle (modelo 2, a relação com o AAC é menor (effect size de 0,229), mas ainda estatisticamente significativo e longe de ser desprezível. Esses resultados convergem com aqueles encontrados por Sammons et al. (2015), Rodriguez e Tamis-LeMonda (2011) e Melhuish et al. (2008). Indicam que o AAC pode ser uma medida promissora para uso em pesquisas de larga-escala a fim de identificar como o contexto familiar pode impactar o desenvolvimento cognitivo das crianças no início da escolarização. Fazemos uma ressalva de que uma medida de AAC não tem intuito classificatório ou de juízo de valor das interações entre pais e crianças. Busca-se, com ela, entender como o ambiente de aprendizagem proporcionado pela família pode se impulsionar às vivências do ambiente escolar e, consequentemente, traduzir-se em vantagens escolares para as crianças. 
É interessante destacar que, ao medir o AAC por meio de atividades realizadas, pode-se estar medindo e abarcando uma série de outros fatores para além do ensino explícito, fatores esses existentes nas atividades em si. Ou seja, o indicador pode estar captando pontos-chave para o desenvolvimento das crianças pequenas, como a existência de momentos de interação e afeto entre adultos e crianças (PERES; BAUER, 2018), conversas descontextualizadas, atenção conjunta em dado objeto e trocas que envolvem muitas perguntas (HOFF, 2006; RODRIGUEZ; TAMIS-LEMONDA, 2011).

Enfatizamos, também, o efeito idade (medido em meses) em relação ao desenvolvimento cognitivo (effect sizes de 0,729 e 0,747 para linguagem e matemática, respectivamente). Tal resultado converge com a intensidade do processo de aprendizagem nessa faixa etária, assim como o forte efeito de maturação das crianças. Estudos sobre o desenvolvimento cognitivo de crianças pequenas (FOX; LEVITT; NELSON, 2010; KNUDSEN, 2004) revelam que a plasticidade do cérebro humano é maior nos primeiros cinco anos de vida. Isso significa que, na primeira infância, é mais fácil e menos custoso para o cérebro criar novas conexões neurais diante dos fatores do ambiente. Durante esse período, há uma janela crítica de desenvolvimento das capacidades sensoriais (visão, audição) e cognitivas, como linguagem, atenção, memória, planejamento, raciocínio lógico-matemático e juízo crítico (SHONKOFF; PHILLIPS, 2000; FOX; LEVITT; NELSON, 2010).

As Tabelas 7 e 8 apresentam resultados de regressões lineares multinível (criança no nível 1 e escola no nível 2), que estimam a relação do AAC com o desenvolvimento cognitivo das crianças durante o primeiro e o segundo anos na pré-escola. Para o primeiro ano da pré-escola, as variáveis dependentes/de interesse utilizadas foram as medidas de linguagem e matemática calculadas com os dados coletados durante a onda 2 (fim do primeiro ano da pré-escola). Para o segundo ano da pré-escola, os modelos estimavam as medidas coletadas durante a onda 3 (fim do segundo ano da pré-escola). Os modelos incluem primeiro somente o indicador de AAC (modelos 1), depois inserem controles sociodemográficos das crianças no nível 1 e variáveis relacionadas à composição do alunado no nível 2/escola (modelos 2). Por fim, acrescentam a variável referente ao nível de desenvolvimento cognitivo anterior das crianças (modelos 3 ).

$\mathrm{Na}$ Tabela 7, observamos que os coeficientes para o indicador AAC nos modelos que estimam linguagem são estatisticamente significativos no primeiro e no segundo anos da pré-escola, mesmo com a inserção de variáveis relacionadas às características das crianças e à composição do alunado (modelos 2). Nesses modelos, os tamanhos do efeito ainda são moderados (0,304 para o primeiro ano na pré-escola e 0,331 para o segundo). Os modelos 3 para primeiro e segundo anos na pré-escola têm valor agregado e incluem a medida anterior de linguagem (medida das ondas 1 e 2, respectivamente), além das variáveis de controle nos níveis da criança e da escola presentes no modelo 2. Nesses modelos, a associação do AAC observada é menor (effect size de 0,123 e 0,146 para primeiro e segundo anos da pré-escola, respectivamente), porém ainda estatisticamente significativa e pedagogicamente relevante. Esse resultado indica que o indicador de AAC está associado não somente às medidas de linha de base, no início da pré-escola, mas parece estar associado também ao desenvolvimento cognitivo das crianças durante os dois anos dessa etapa da educação.

A associação entre o AAC e o desenvolvimento cognitivo das crianças na medida de matemática é apresentada na Tabela 8. Os coeficientes são similares aos obtidos com os modelos que estimam as medidas de linguagem no fim do primeiro e do segundo anos na pré-escola. O AAC apresenta coeficientes positivos e estatisticamente significativos em todos os modelos estimados. $\mathrm{O}$ tamanho da associação observada nos modelos de valor agregado (modelos 3) são menores no fim do primeiro e do segundo anos da pré-escola (effect sizes de 0,152 e 0,126 , respectivamente) se comparados com 
Tabela 7. Modelos de regressão linear multinível estimando medidas de linguagem no fim do primeiro ano (onda 2) e no fim do segundo ano (onda 3) da pré-escola

\begin{tabular}{|c|c|c|c|c|c|c|}
\hline & \multicolumn{3}{|c|}{$1^{\circ}$ ano da pré-escola } & \multicolumn{3}{|c|}{$2^{\circ}$ ano da pré-escola } \\
\hline & Modelo 1 & Modelo 2 & Modelo 3 & Modelo 1 & Modelo 2 & Modelo 3 \\
\hline \multirow{2}{*}{$\begin{array}{c}\text { Baixa } \\
\text { escolaridade } \\
\text { (prop. escola) }\end{array}$} & & $-0,040$ & $-0,015$ & & 0,003 & 0,010 \\
\hline & & $(-0,101-0,022)$ & $(-0,064-0,035)$ & & $(-0,075-0,081)$ & $(-0,052-0,072)$ \\
\hline \multirow{2}{*}{$\begin{array}{c}\text { Cor } \\
\text { (prop. negros } \\
\text { escola) }\end{array}$} & & $-0,010$ & $-0,009$ & & $-0,030$ & $-0,008$ \\
\hline & & $(-0,076-0,055)$ & $(-0,063-0,044)$ & & $(-0,111-0,051)$ & $(-0,074-0,058)$ \\
\hline \multirow{2}{*}{$\begin{array}{c}\text { Pobreza } \\
\text { (prop. escola) }\end{array}$} & & $-0,057^{\star}$ & $-0,041$ & & $-0,083^{\star}$ & $-0,031$ \\
\hline & & $(-0,125-0,012)$ & $(-0,097-0,015)$ & & $(-0,174-0,008)$ & $(-0,103-0,041)$ \\
\hline \multirow{2}{*}{$\begin{array}{l}\text { Medida } \\
\text { (onda 1) }\end{array}$} & & & $0,541^{\star \star \star}$ & & & \\
\hline & & & $(0,509-0,573)$ & & & \\
\hline \multirow{2}{*}{$\begin{array}{l}\text { Medida } \\
\text { (onda 2) }\end{array}$} & & & & & & $0,676^{\star * *}$ \\
\hline & & & & & & $(0,643-0,708)$ \\
\hline \multirow{2}{*}{$\mathrm{AAC}$} & $0,166^{* * *}$ & $0,123^{\star * *}$ & $0,035^{\star}$ & $0,182^{* * *}$ & $0,141^{\star * *}$ & $0,043^{\star *}$ \\
\hline & $(0,126-0,205)$ & $(0,083-0,163)$ & $(0,003-0,067)$ & $(0,143-0,221)$ & $(0,100-0,182)$ & $(0,011-0,074)$ \\
\hline \multirow{2}{*}{ Idade } & & $0,262^{\star * *}$ & $0,090^{* * *}$ & & $0,249^{* * *}$ & $0,073^{* * \star}$ \\
\hline & & $(0,219-0,304)$ & $(0,055-0,125)$ & & $(0,205-0,293)$ & $(0,036-0,109)$ \\
\hline \multirow{2}{*}{$\begin{array}{c}\text { Sexo } \\
\text { (menino) }\end{array}$} & & $-0,151^{\star \star}$ & $-0,011$ & & $-0,189^{\star \star \star \star}$ & $-0,080^{\star *}$ \\
\hline & & $(-0,227--0,075)$ & $(-0,070-0,048)$ & & $(-0,265--0,111)$ & $(-0,137--0,020)$ \\
\hline \multirow{2}{*}{$\begin{array}{c}\text { Cor } \\
\text { (negra) }\end{array}$} & & $-0,100^{\star \star}$ & $-0,048^{\star}$ & & $-0,086^{*}$ & $-0,040$ \\
\hline & & $(-0,179--0,019)$ & $(-0,109-0,013)$ & & $(-0,166--0,005)$ & $(-0,101-0,020)$ \\
\hline \multirow{2}{*}{$\begin{array}{c}\text { Baixa } \\
\text { escolaridade }\end{array}$} & & $-0,233^{\star \star \star}$ & $-0,118^{\star \star \star}$ & & $-0,304^{\star * \star}$ & $-0,120^{\star * *}$ \\
\hline & & $(-0,315--0,151)$ & $(-0,182-0,053)$ & & $(-0,388-0,219)$ & $(-0,183--0,056)$ \\
\hline \multirow{2}{*}{ Pobreza } & & $-0,059$ & $-0,020$ & & $-0,124^{\star \star}$ & $-0,068^{\star}$ \\
\hline & & $(-0,140-0,021)$ & $(-0,082-0,043)$ & & $(-0,206-0,042)$ & $(-0,130--0,006)$ \\
\hline LogLikelihood & $-2477,868$ & $-2152,754$ & $-1317,062$ & $-3058,074$ & $-2407,296$ & $-1417,498$ \\
\hline AIC & 4903,736 & 4329,508 & 2660,124 & 6124,149 & 4838,591 & 2860,996 \\
\hline N Alunos & 1929 & 1772 & 1498 & 2269 & 1895 & 1575 \\
\hline N Escolas & 46 & 46 & 46 & 46 & 46 & 46 \\
\hline
\end{tabular}

aqueles observados nos modelos 1 e 2, que não incluem controle da medida anterior. Ainda assim, os coeficientes nos modelos 3 permanecem estatisticamente significativos novamente apontando que o indicador de AAC está associado ao desenvolvimento das crianças durante a pré-escola. Vale ressaltar que, sem a inserção do controle das medidas anteriores (onda 1 para o primeiro ano da pré-escola e onda 2 para o segundo), os modelos superestimariam um potencial efeito do AAC sobre o desenvolvimento em linguagem e matemática das crianças durante a pré-escola. Os resultados reforçam a importância de estudos com desenhos longitudinais que permitam a construção de modelos de valor agregado (valueadded) para estimar o impacto do AAC e/ou o efeito da escola sobre o desenvolvimento das crianças.

Os resultados observados no contexto brasileiro convergem com estudos longitudinais realizados com crianças dessa faixa etária em outros contextos, como o EPPE (SYLVA et al, 2010; SAMMONS et al., 2015; MELHUISH et al., 2008) e o realizado por Rodriguez E Tamis-LeMonda (2011). 
Tabela 8. Modelos de regressão linear multinível estimando medidas de matemática no fim do primeiro ano (onda 2) e no fim do segundo ano (onda 3) da pré-escola

\begin{tabular}{|c|c|c|c|c|c|c|}
\hline & \multicolumn{3}{|c|}{$1^{\circ}$ ano da pré-escola } & \multicolumn{3}{|c|}{$2^{\circ}$ ano da pré-escola } \\
\hline & Modelo 1 & Modelo 2 & Modelo 3 & Modelo 1 & Modelo 2 & Modelo 3 \\
\hline \multirow{2}{*}{$\begin{array}{l}\text { Baixa escolaridade } \\
\text { (prop. escola) }\end{array}$} & & $-0,063$ & 0,007 & & $-0,036$ & 0,001 \\
\hline & & $(-0,154-0,028)$ & $(-0,056-0,071)$ & & $(-0,136-0,064)$ & $(-0,064-0,066)$ \\
\hline \multirow{2}{*}{$\begin{array}{c}\text { Cor } \\
\text { (prop. negros escola) } \\
\end{array}$} & & $-0,038$ & $-0,021$ & & $-0,042$ & $-0,008$ \\
\hline & & $(-0,135-0,060)$ & $(-0,089-0,049)$ & & $(-0,147-0,064)$ & $(-0,077-0,061)$ \\
\hline \multirow{2}{*}{$\begin{array}{c}\text { Pobreza } \\
\text { (prop. escola) }\end{array}$} & & $-0,036$ & $-0,036$ & & $-0,030$ & 0,001 \\
\hline & & $(-0,138-0,066)$ & $(-0,105-0,033)$ & & $(-0,144-0,084)$ & $(-0,070-0,071)$ \\
\hline \multirow{2}{*}{$\begin{array}{c}\text { Medida } \\
\text { (onda 1) }\end{array}$} & & & $0,948^{\star * *}$ & & & \\
\hline & & & $(0,896-0,999)$ & & & \\
\hline \multirow{2}{*}{$\begin{array}{l}\text { Medida } \\
\text { (onda 2) }\end{array}$} & & & & & & $1,123^{* * *}$ \\
\hline & & & & & & $(1,071-1,174)$ \\
\hline \multirow{2}{*}{$\mathrm{AAC}$} & $0,273^{\star * *}$ & $0,193^{\star * *}$ & $0,068^{\star *}$ & $0,279^{* * *}$ & $0,225^{* * *}$ & $0,059^{*}$ \\
\hline & $(0,212-0,334)$ & $(0,131-0,256)$ & $(0,019-0,117)$ & $(0,215-0,342)$ & $(0,158-0,292)$ & $(0,009-0,109)$ \\
\hline \multirow{2}{*}{ Idade } & & $0,435^{\star \star \star}$ & $0,145^{\star * \star}$ & & $0,483^{\star \star \star}$ & $0,120^{* * *}$ \\
\hline & & $(0,370-0,501)$ & $(0,091-0,199)$ & & $(0,412-0,554)$ & $(0,062-0,176)$ \\
\hline \multirow{2}{*}{$\begin{array}{c}\text { Sexo } \\
(\text { menino })\end{array}$} & & $-0,081$ & 0,044 & & $0,105^{\star}$ & $0,178^{\star * \star}$ \\
\hline & & $(-0,198-0,036)$ & $(-0,047-0,134)$ & & $(-0,021-0,230)$ & $(0,086-0,270)$ \\
\hline \multirow{2}{*}{$\begin{array}{c}\text { Cor } \\
\text { (negra) }\end{array}$} & & $-0,214^{* * *}$ & $-0,064$ & & $-0,147^{\star}$ & $-0,011$ \\
\hline & & $(-0,338--0,091)$ & $(-0,158-0,032)$ & & $(-0,278--0,016)$ & $(-0,107-0,085)$ \\
\hline \multirow{2}{*}{$\begin{array}{c}\text { Baixa } \\
\text { escolaridade }\end{array}$} & & $-0,467^{* * *}$ & $-0,154^{\star *}$ & & $-0,434^{* * *}$ & $-0,065$ \\
\hline & & $(-0,593--0,338)$ & $(-0,254--0,053)$ & & $(-0,570--0,296)$ & $(-0,165-0,037)$ \\
\hline \multirow{2}{*}{ Pobreza } & & $-0,164^{\star}$ & $-0,040$ & & $-0,211^{* * *}$ & $-0,095^{\star}$ \\
\hline & & $(-0,289--0,039)$ & $(-0,136-0,057)$ & & $(-0,346--0,078)$ & $(-0,194-0,002)$ \\
\hline LogLikelihood & $-3297,020$ & $-2924,152$ & $-1960,340$ & $-4153,619$ & $-3320,895$ & $-2125,255$ \\
\hline AIC & 6602,040 & 5872,303 & 3946,680 & 8315,238 & 6665,790 & 4276,511 \\
\hline N Alunos & 1929 & 1772 & 1498 & 2269 & 1895 & 1575 \\
\hline $\mathrm{N}$ Escolas & 46 & 46 & 46 & 46 & 46 & 46 \\
\hline
\end{tabular}

Notas: ${ }^{* * *} \mathrm{p}<0,001 ;{ }^{* *} \mathrm{p}<0,01 ;{ }^{\star} \mathrm{p}<0,05 ;+\mathrm{p}<0,10$. A tabela apresenta os coeficientes e os intervalos de confiança estimados; Fonte: Elaboração própria.

\section{Considerações Finais}

No Brasil, a maior parte dos estudos na área da educação infantil sobre a relação família-escola focam nas divergências entre as concepções de professores e responsáveis sobre a educação de crianças pequenas (RODRIGUES; MUANIS, 2020). No que tange à produção no campo da sociologia da educação, observamos poucos estudos que versem sobre fatores extraescolares associados ao desenvolvimento das crianças na educação infantil. Nosso estudo apresenta uma análise inovadora, não apenas por estudar como as desigualdades sociais se apesentam já no início da escolarização obrigatória, mas também por utilizar um indicador de AAC, o qual buscou captar aspectos mais processuais da interação adulto-criança, para além das medidas estruturais relacionadas à origem socioeconômica das famílias, que são mais comumente utilizadas em estudos no campo da sociologia da educação brasileira. Os resultados encontrados indicam que o AAC se mostrou relevante para compreender o ponto de partida das crianças e continuou sendo uma variável que 
contribui para explicar o desenvolvimento dessas durante os dois primeiros anos da escolarização obrigatória, mesmo ao levar em consideração crianças com características sociodemográficas parecidas (cor, idade e sexo das crianças, escolaridade dos responsáveis e pobreza). Esse resultado aponta para a relevância de incluir características da rotina e da dinâmica da família nessa equação, já que os adultos de referência da criança são parte do seu contexto mais próximo e podem criar oportunidades de aprendizado significativas para elas.

Destaca-se que o conceito de home learning environment não pode ser confundido com homeschooling (educação domiciliar), pois tem sido utilizado justamente para melhorar a precisão das análises sobre a trajetória e os processos da criança na instituição escolar. Além disso, discutir sobre desigualdades educacionais no início da escolarização requer uma atenção às formas como os ambientes familiares e escolares conversam, bem como às adaptações que as crianças precisam fazer para transitar nesses dois ambientes. Esse debate necessita de uma abordagem aprofundada para que sejam evitadas interpretações simplistas, que visem escolarizar o ambiente familiar ou culpar as famílias pelas desigualdades existentes, responsabilizando-as por compensarem problemas sociais profundos. Melhoras no AAC não ocorrem de forma isolada de um contexto social maior e da comunidade de que as famílias fazem parte. Nesse sentido, uma importante contribuição do presente trabalho e de estudos que versam sobre o AAC é incentivar e informar o desenvolvimento de políticas públicas e práticas escolares que apoiem e orientem as famílias como educadores e cuidadores, visando ao maior sucesso na experiência escolar das crianças. Intervenções que busquem estimular o AAC das crianças devem levar em consideração as várias limitações e dificuldades encontradas pelas famílias, como longas jornadas de trabalho dos responsáveis, situações de extrema pobreza, saúde mental dos membros familiares, violência doméstica e no entorno da residência, condições de moradia etc. (SMEES; SAMMONS, 2017; BRITTO et al., 2015). Tal contexto requer que as estratégias de promoção de AAC sejam acompanhadas por políticas intersetoriais mais amplas de apoio às crianças e às suas famílias. Nesse sentido, chamamos atenção para alguns estudos que avaliaram o impacto de programas com foco em estimular interações e atividades realizadas no contexto familiar. Os temas tratados são diversos, como hábitos e alimentação saudáveis, cuidados de saúde, importância do aleitamento materno, necessidade de afeto e vínculos positivos, a enorme capacidade de aprendizagem das crianças e como ter interações que estimulem o desenvolvimento dessas (PERES; BAUER, 2018). Alguns programas que possuem foco mais específico em melhorar as interações e atividades realizadas no contexto familiar encontraram resultados positivos sobre o desenvolvimento cognitivo de crianças na pré-escola (BARLETT et al., 2016; BRITTO et al., 2015; WEISLEDER et al., 2018).

Por sua vez, as instituições de educação infantil possuem uma janela de oportunidade significativa para dialogar com as famílias sobre o processo de aprendizagem e desenvolvimento das crianças. Programas que visem empoderar as escolas e oferecer condições para que possam apoiar as famílias na criação de ambientes de aprendizagem em casa podem ser parte fundamental na implementação de políticas que buscam alcançar o AAC. Considerando que a expansão e a elaboração de marcos regulatórios e diretrizes curriculares para educação infantil no Brasil são muito recentes, vários responsáveis tiveram pouco ou nenhum contato ou experiência com esse nível de educação e suas práticas pedagógicas específicas, norteadas pelos eixos das interações e brincadeiras. Tal realidade reforça o protagonismo dos centros de educação infantil na elaboração de estratégias de promoção de relações família-escola mais próximas e na orientação dos responsáveis para a realização de atividades como leitura de livros infantis e outras atividades lúdicas, incluindo brincadeiras com rimas, letras, números, entre outras.

Por fim, a compreensão da relação entre o AAC e o desenvolvimento das crianças no início da escolarização obrigatória torna-se ainda mais relevante no contexto de pandemia. O longo período de fechamento das escolas experimentado no contexto brasileiro, bem como as limitações já observadas por 
pesquisas para a instituição do ensino remoto (CAMPOS; VIEIRA, 2021; BARBERIA; CANTANELLI; SCHMALZ, 2021), apresentou barreiras para que as escolas pudessem oferecer oportunidades de aprendizagem para as crianças, em especial aquelas que vivem em contextos mais vulneráveis. Portanto, partimos do pressuposto de que as oportunidades oferecidas pelas famílias ganharão ainda maior peso como preditores do desenvolvimento das crianças durante a pandemia e, portanto, podemos esperar um acirramento das desigualdades já existentes no início da escolarização obrigatória (BARTHOLO et al., 2020b; KOSLINSKI; BARTHOLO, 2020). Novamente, o presente estudo se soma às evidências já existentes sobre desenvolvimento infantil que sugerem a importância de se pensar políticas públicas intersetoriais que auxiliem as famílias a apoiarem as crianças, principalmente quando se trata de grupos em vulnerabilidade social.

\section{Contribuições dos Autores}

Problematização e conceituação: Koslinski MC, Gomes RC, Rodrigues BLC; Metodologia: Koslinski MC, Bartholo TL, Andrade FM; Análise: Koslinski MC, Andrade FM; Redação: Koslinski MC, Gomes RC, Rodrigues BLC, Andrade FM, Bartholo TL.

\section{Notas}

1. A pesquisa Geres 2005 foi o principal estudo longitudinal em larga escala na área da educação realizado no contexto brasileiro. Realizada há mais de quinze anos, a pesquisa focou nos anos iniciais no Ensino Fundamental (BROOKE; BONAMINO, 2011).

2. Por exemplo, estudo recente de Carvalho e Nogueira (2020), desenvolvido no campo da sociologia da educação, com crianças de 3 a 11 anos, identificou que, entre famílias com maior capital cultural, crianças tinham uma organização do espaço do quarto com maior conformidade com demandas da cultura escolar. No entanto, o estudo não tenta relacionar tais práticas ao desenvolvimento das crianças.

3. O instrumento busca identificar recursos do ambiente familiar que possam contribuir para o aprendizado acadêmico nos anos iniciais do Ensino Fundamental em múltiplas dimensões, como: passeios, brinquedos, livros, atividades previsíveis (rotinas regulares da família) e práticas parentais.

4. Medido por sete itens do RAF: o que a criança faz quando não está na escola; passeios realizados nos últimos doze meses; atividades compartilhadas com os pais em casa; variedade de brinquedos e livros disponíveis; rotinas diárias com horário definido; momentos do dia e da semana em que a família se reúne.

5. Ao longo do texto, intercalamos o uso dos termos "pré-escola" e "educação infantil". Reconhecemos o debate no campo e a defesa pelo termo educação infantil. Entretanto, achamos importante indicar de forma clara o recorte e o escopo do estudo, que não incluem crianças de $0 \mathrm{a} 3$ anos. O presente estudo focou em crianças que tinham 4 anos em 2017 e estavam, portanto, no início da escolarização obrigatória, de acordo com a Emenda Constitucional n. 59, de 11 de novembro de 2009.

6. Para mais detalhes sobre a amostra, ver Autor (KOSLINSKI; BARTHOLO, 2019; BARTHOLO et al., 2020a;).

7. Partimos do pressuposto de que o AAC pode ser influenciado por diversos fatores: origem socioeconômica da criança; experiência prévia e conhecimento da família sobre a educação infantil; programas educacionais; ações da escola para incentivar interações entre crianças-responsáveis; entre outros fatores. No entanto, no questionário, buscamos compreender somente se alguém da família realizava ou não as atividades anteriormente descritas com a criança, sem identificar se as atividades haviam sido iniciativas das próprias famílias ou realizadas a partir de orientações das escolas. 
8. Itens em que a soma das respostas não completa $100 \%$ indicam dados faltantes. A ausência de resposta pode ter sido em função do desconhecimento sobre determinada atividade ter sido realizada, sobre a posse de itens ou por opção de não responder àquela questão.

9. As correlações podem ser consideradas de baixas a moderadas, porém é importante destacar que são consistentes ao longo do tempo (três medidas sobre o desenvolvimento cognitivo) e estatisticamente significativas. Quando comparamos com outros achados no campo da educação que associam medidas sobre o perfil da família com o desenvolvimento cognitivo, observamos que o tamanho dos coeficientes é relevante dos pontos de vista pedagógico e do desenvolvimento das crianças.

10. Os autores sugerem uma interpretação dos effect sizes em meses de progresso escolar, considerando o effect size de um desvio-padrão como equivalente a um ano de instrução na educação elementar.

\section{Referências}

ANDRADE, S. A. et al. Ambiente familiar e desenvolvimento cognitivo infantil: uma abordagem epidemiológica. Revista de Saúde Pública, São Paulo, v. 39, n. 4, p. 606-611, 2005. https://doi.org/10.1590/ S0034-89102005000400014

BARBERIA, L. G.; CANTANELLI, L. G.; SCHMALZ, P. H. S. Uma avaliação dos programas de educação pública dos estados e capitais brasileiras durante a pandemia do COVID-19. [S. 1.]: FGV/EESP/CLEAR, 2021. Disponível em: https://remote-learning-in-the-covid-19-pandemic-v-1-0-portuguese-diagramado-1. pdf. Acesso em: 5 maio 2021.

BARTHOLO, T. L. et al. What do children know upon entry to pre-school in Rio de Janeiro? Ensaio: Avaliação e Políticas Públicas em Educação, Rio de Janeiro, v. 28, n. 107, p. 1-22, 2020a. https://doi.org/10.1590/ S0104-40362019002702071

BARTHOLO, T. L. et al. The use of cognitive instruments for research in early childhood education: constraints and possibilities in the Brazilian context. Pro-Posições, Campinas, v. 31, 2020b, p. 1-24. https:// doi.org/10.1590/1980-6248-2018-0036

BARTLETT, J. et al. Compendium of parenting interventions. Washington, D.C.: National Center on Parent, Family, and Community Engagement/Office of Head Start/U.S. Department of Health \& Human Services, 2016.

BONAMINO, A. M. C. et al. Os efeitos das diferentes formas de capital no desempenho escolar: um estudo à luz de Bourdieu e de Coleman. Revista Brasileira de Educação, Rio de Janeiro, v. 15, n. 45, p. 487-499, 2010. https://doi.org/10.1590/S1413-24782010000300007

BOONE, W. J. Rasch analysis for instrument development: why, when, and how? CBE Life Sciences Education, Rockville Pike, v. 15, n. 4, p. 1-7, 2016. https://doi.org/10.1187/cbe.16-04-0148

BOURDIEU, P. Os três estados do capital cultural. In: NOGUEIRA, M. A.; CATANI, A. (orgs.). Escritos de educação. Petrópolis: Vozes, 1988. p. 71-79.

BRASIL. Lei n. 13.005, de 24 de junho de 2014. Aprova o Plano Nacional de Educação - PNE e dá outras providências. Brasília, DF: Presidência da República, 2014. 
BRITTO, P. et al. A systematic review of parenting programmes for young children in low- and middleincome countries. New York: United Nation’s Children Emergency Fund/UNICEF, 2015.

BRONFENBRENNER, U. Ecological systems theory. In: R. VASTA (ed.), Annals of child development. Greenwich, CT: JAI Press, 1989. v. 6, p. 187-249.

BRONFENBRENNER, U.; MORRIS, P. A. The bioecological model of human development. In: DAMON, W.; LERNER, R. M. (eds.), Handbook of child psychology: theoretical models of human development. 6. ed. New York: John Wiley, 2006.

BROOKE, N.; SOARES, J. F. (orgs.). Pesquisa em eficácia escolar: origem e trajetórias. Belo Horizonte: Editora UFMG, 2008.

BROOKE, N.; BONAMINO, A. (orgs.). Geres 2005: razões e resultados de uma pesquisa longitudinal sobre a eficácia escolar. Rio de Janeiro: Walprint, 2011.

CACHAPUZ R. F.; HALPERN R. A influência das variáveis ambientais no desenvolvimento da linguagem em uma amostra de crianças. Revista da AMRIGS, Porto Alegre, v. 40, n.4, p. 292-301, 2006.

CAMPOS, M. M.; VIERA, L. F. Covid-19 and early childhood in Brazil: impacts on children's well-being, education and care. European Early Childhood Education Research Journal, Abingdon, v. 29, Jan. 2021, p. 1-16. https://doi.org/10.1080/1350293X.2021.1872671

CARVALHO, C. N.; NOGUEIRA, M. A. "Nascer em berço de ouro": o quarto infantil como instância socializatória. Educação \& Sociedade, Campinas, v. 41, p. 1-19, 2020. https://doi.org/10.1590/ES.234058

CASTRO, C. Avaliação do aprendizado no ciclo de alfabetização de alunos da rede municipal do Rio de Janeiro. 2016. Dissertação (Mestrado em População, Território e Estatísticas Públicas) - Instituto Brasileiro de Geografia e Estatística. Escola Nacional de Ciência Estatística, Rio de Janeiro, 2016.

CRAHAY, M.; BAYE, A. Existem escolas justas e eficazes? Esboço de resposta baseado no PISA 2009. Cadernos de Pesquisa, São Paulo, v. 43, n. 150, p. 858-883, 2013. https://doi.org/10.1590/S0100-15742013000300007

FERREIRA, S. H. A.; BARRERA, S. D. Ambiente familiar e aprendizagem escolar em alunos da educação infantil. Psico, Porto Alegre, v. 41, n. 4, p. 462-472, 2010.

FOX S.; LEVITT, P.; NELSON C. A. How the timing and quality of early experiences influence the development of brain architecture. Child Development, Rockville Pike, v. 81, n. 1, p. 28-40, 2010. https:// doi.org/10.1111/j.1467-8624.2009.01380.x

FRANCO, C. et al. Qualidade e equidade em educação: reconsiderando o significado de "fatores intraescolares”. Ensaio: Avaliação e Políticas Públicas em Educação, Rio de Janeiro, v. 15, n. 55, p. 277-297, 2007. https://doi.org/10.1590/S0104-40362007000200007

HATTIE, J. Visible learning: a synthesis of over 800 meta-analyses relating to achievement. New York: Routledge, 2009.

HIGGINS, S.; KOKOTSAKY, D.; COE, R. Technical appendices. Teaching and learning toolkit. [S. 1.]: The Sutton Trust/Education Endowment Foundation, fev. 2014. Disponível em: www.cplp.eu/en/ download/1404046919/?at=1. Acesso em: 3 fev. 2019. 
HOFF, E. How social contexts support and shape language development. Developmental Review, Orlando, v. 26, n. 1, p. 55-88, 2006. https://doi.org/10.1016/j.dr.2005.11.002

HOFF, E. The specificity of environmental influence: socioeconomic status affects early vocabulary development via maternal speech. Child Development, Rockville Pike, v. 74, n. 5, p. 1368-1378, 2003. https:// doi.org/10.1111/1467-8624.00612

KNUDSEN, E. I. Sensitive periods in the development of the brain and behavior. Journal of Cognitive Neuroscience, Cambridge, MA, v. 16, n. 8, p. 1412-1425, 2004. https://doi.org/10.1162/0898929042304796

KOSLINSKI, M. C.; BARTHOLO, T. L. Impacto dos espaços de desenvolvimento infantil no primeiro ano na pré-escola. Estudos em Avaliação Educacional, São Paulo, v. 30, n. 73 p. 280-311, 2019. https://doi. org/10.18222/eae.v30i73.5850

KOSLINSKI, M. C.; BARTHOLO, T. L. Desigualdades de oportunidades educacionais no início da trajetória escolar no contexto brasileiro. Lua Nova, São Paulo, n. 110, p. 215-245, 2020. https://doi. org/10.1590/0102-215245/110

LINACRE, J. M. Winsteps Rasch measurement computer program user's guide. Oregon: Beaverton, 2020. MARTURANO, E. M. O inventário de recursos do ambiente familiar. Psicologia: Reflexão e Crítica, Porto Alegre, v. 19, n. 3, p. 498-506, 2006. https://doi.org/10.1590/S0102-79722006000300019

MARTURANO, E. M. et al. Effects of the home learning environment and preschool center experience upon literacy and numeracy development in early primary school. Journal of Social Issues, Malden, v. 64, n.1, p. 95-114, 2008. https://doi.org/10.1111/j.1540-4560.2008.00550.x

MARTURANO, E. M.; TRIVELLATO-FERREIRA, M. C. Recursos da criança, da família e da escola predizem competência na transição da $1^{a}$ série. Revista Interamericana de Psicología/Interamerican Journal of Psychology, Porto Alegre, v. 42, n. 3, p. 549-558, 2008.

MELHUISH, E. et al. Effects of the Home Learning Environment and preschool center experience upon literacy and numeracy development in early primary school. Journal of Social Issues, Maiden, v. 64, n. 1, p. 95-114, 2008. https://doi.org/10.1111/j.1540-4560.2008.00550.x

NOGUEIRA, M. A. O capital cultural e a produção das desigualdades escolares contemporâneas. Cadernos de Pesquisa, São Paulo, p. 1-13, v. 51, 2021. https://doi.org/10.1590/198053147468

NATIONAL LITERACY TRUST; NATIONAL CHILDREN'S BUREAU; PEEPLE; FOUNDATION YEARS TRUST. Home Matters: making the most of the home learning environment. Guidance for schools, nurseries, local authorities and public health partners. London: National Children's Bureau, 2018. Disponível em: https://www.ncb.org.uk/sites/default/files/field/attachment/HLE_doc.pdf. Acesso em: 10 nov. 2020.

OPNE [OBSERVATÓRIO DO PLANO NACIONAL DE EDUCAÇÃO]. Observatoriodopne.org.br, [s. d.]. Disponível em: https://www.observatoriodopne.org.br. Acesso em: 10 nov. 2020.

PERES, A., BAUER, M. Da ciência à prática: os programas de apoio ao desenvolvimento infantil na América Latina. São Paulo: Cross Content, 2018. 
RAIKES, H. et al. Mother-child book reading in low-income families: correlates and outcomes during the first three years of life. Child Development, Rockville Pike, v. 77, n. 4, p. 924-953, 2006. https://doi. org/10.1111/j.1467-8624.2006.00911.x

RODRIGUES, B. L. C.; MUANIS, M. C. A relação família e escola na educação infantil. Revista Contemporânea de Educação, Rio de Janeiro, v. 15, n. 33, p. 73-91, maio/ago. 2020. https://doi.org/10.20500/v15i33.37395

RODRIGUEZ, E. T. et al. The formative role of home literacy experiences across the first three years of life in children from low-income families. Journal of Applied Developmental Psychology, Amsterdam, v. 30, n. 6, p. 677-694, 2009. https://doi.org/10.1016/j.appdev.2009.01.003

RODRIGUEZ, E. T.; TAMIS-LEMONDA, C. S. Trajectories of the home learning environment across the first 5 years: associations with children's vocabulary and literacy skills at prekindergarten. Child Development, Rockville Pike, v. 82, n. 4, p. 1058-1075, 2011. https://doi.org/10.1111/j.1467-8624.2011.01614.x

ROWE, M. L. A longitudinal investigation of the role of quantity and quality of child-directed speech in vocabulary development: child-directed speech and vocabulary. Child Development, Rockville Pike, v. 83, n. 5, p. 1762-1774, 2012. https://doi.org/10.1111/j.1467-8624.2012.01805.x

SAMMONS, P. et al. Influences on children's attainment and progress in key stage 2: cognitive outcomes in year 6. Effective pre-school and primary education 3-11 Project (EPPE 3-11). Research Report n. DCSF-RR048. Nottingham: Department for Children, Schools and Families, 2008.

SAMMONS, P. et al. The long-term role of the home learning environment in shaping students' academic attainment in secondary school. Journal of Children's Services, [s. 1.], v. 10, n. 3, p. 189-201, 2015. https:// doi.org/10.1108/JCS-02-2015-0007

SHONKOFF, J. P.; PHILLIPS, D. A. (eds.). From neurons to neighborhoods: the science of early childhood development. Washington, DC: The National Academies Press, 2000.

SIRIN, S. R. Socioeconomic status and academic achievement: a meta-analytic review of research. Review of Educational Research, Washington, DC, v. 75, n. 3, p. 417-453, 2005. https://doi. org/10.3102/00346543075003417

SMEES, R; SAMMONS, P. What role does the home learning environment play in supporting good child development in the early years and positive outcomes in later life? London: Action for Children, 2017.

SNOW, C. E.; BURNS, S.; GRIFFIN, P. Preventing reading difficulties in young children. Washington, DC: National Academy Press, 1998.

SOARES, J. F. Qualidade e equidade na educação básica brasileira: a evidência do SAEB-2001. Archivos Analíticos de Políticas Educativas/Education Policy Analysis Archives, Tempe, v. 12, n. 38, p. 1-24, 2004.

SOARES, T. M. et al. Modelos de valor agregado para medir a eficácia das escolas Geres. Ensaio: Avaliação e Políticas Públicas em Educação, Rio de Janeiro, v. 25, n. 94, p. 59-89, 2017. https://doi.org/10.1590/ S0104-40362017000100003

SYLVA, K. et al. Early childhood matters: evidence from the effective pre-school and primary education project. London: Routledge, 2010. 
TAGGART, B. et al. O poder da pré-escola: evidências de um estudo longitudinal na Inglaterra. Cadernos de Pesquisa, São Paulo, v. 41, n. 142, p. 68-99, 2011. https://doi.org/10.1590/S0100-15742011000100005

TYMMS, P. Baseline assessment and monitoring in primary schools: achievements, attitudes and valueadded indicators. London: David Fulton, 1999.

TYMMS, P. Effect sizes in multilevel models. In: SCHAGEN, I.; ELLIOT, K. (orgs.). But what does it mean? The use of effect sizes in educational research. Slough, UK: National Foundation for Educational Research, 2004.

WEISLEDER, A. et al. Reading aloud and child development: a cluster-randomized trial in Brazil. Pediatrics, Evanston, v. 141, n. 1, 2018. https://doi.org/10.1542/peds.2017-0723

\section{Sobre os Autores}

Mariane Campelo Koslinski é graduada em Sociologia pela London School of Economics e Doutora em Sociologia pela Universidade Federal do Rio de Janeiro, com período Sanduiche na Columbia University. Atualmente, é professora associada da Faculdade de Educação e do Programa de Pós-graduação em Educação e coordenadora do Laboratório de Pesquisa em Oportunidades Educacionais, ambos da UFRJ. Tem experiência em pesquisa na área de sociologia da educação, com ênfase em avaliação educacional; análise de políticas educacionais; desigualdades de oportunidades educacionais; e segregação socioespacial e desigualdades educacionais.

Renata Corrêa Gomes é graduada em Pedagogia pela Universidade Federal do Rio de Janeiro e Mestranda na Graduate School of Education da Stanford University. Tem experiência em pesquisa nas áreas de formação de professores, avaliação educacional e desigualdades de oportunidades educacionais.

Blenda Luize Chor Rodrigues é doutoranda na University of North Carolina at Greensboro e graduada em Pedagogia pela Universidade Federal do Rio de Janeiro. Desenvolve pesquisas direcionadas a entender as relações entre a qualidade dos centros de educação infantil e os desenvolvimentos cognitivo e socioemocional das crianças pequenas. Tem experiência em elaboração, tradução e adaptação de instrumentos voltados a medir a qualidade dos contextos proporcionados por centros de educação infantil.

Felipe Macedo de Andrade é graduado em licenciatura em Educação Física e Doutor em Educação, ambos pela Universidade Federal do Rio de Janeiro. Atualmente, é professor do Colégio de Aplicação da UFRJ e coordenador do Curso de Especialização Saberes e Práticas na Educação Básica com ênfase de Educação Física Escolar. Desenvolve pesquisas na área de sociologia da educação com ênfase em avaliação em larga escala; políticas de responsabilização; e os processos de apropriação do uso de dados pelas escolas.

Tiago Lisboa Bartholo é doutor em educação pela Universidade Federal do Rio de Janeiro. Atualmente é professor do Programa de Pós-graduação em Educação da Universidade Federal do Rio de Janeiro e do Colégio de Aplicação da UFRJ. Pesquisador do Laboratório de Pesquisa em Oportunidades Educacionais da mesma instituição. Tem experiência com estudos na área de sociologia da educação com ênfase na temática sobre as desigualdades educacionais; segregação escolar; e avaliação de impacto de programas e políticas educacionais.

Recebido: 08 mar. 2021

Aceito: 12 jul. 2021 


\section{Apêndices}

Tabela 9. Modelos de regressão linear estimando linguagem e matemática na entrada da pré-escola (effect sizes)

\begin{tabular}{|c|c|c|c|c|}
\hline & \multicolumn{2}{|c|}{ Linguagem } & \multicolumn{2}{|c|}{ Matemática } \\
\hline & Modelo 1 & Modelo 2 & Modelo 1 & Modelo 2 \\
\hline $\mathrm{AAC}$ & $0,394^{* * *}$ & $0,308^{* * *}$ & $0,372^{* * *}$ & $0,229^{* * *}$ \\
\hline Idade & & $0,729^{* * *}$ & & $0,747^{* * *}$ \\
\hline Sexo (menino) & & $-0,218^{* * *}$ & & $-0,038$ \\
\hline Cor (negra) & & $-0,099^{+}$ & & $-0,173^{* * *}$ \\
\hline $\begin{array}{l}\text { Baixa escolaridade dos } \\
\text { pais }\end{array}$ & & $-0,290^{* * *}$ & & $-0,470^{* * *}$ \\
\hline Pobreza & & $-0,216^{*}$ & & $-0,172^{* * *}$ \\
\hline $\mathrm{N}$ & 1698 & 1590 & 1698 & 1590 \\
\hline $\mathrm{R} 2$ & 0,037 & 0,151 & 0,033 & 0,172 \\
\hline
\end{tabular}

Nota: ${ }^{* *} \mathrm{p}<0,001 ;{ }^{* *} \mathrm{p}<0,01 ;{ }^{*} \mathrm{p}<0,05 ;+\mathrm{p}<0,10$. Fonte: Elaboração própria dos autores

Tabela 10. Modelos de regressão linear multinível estimando medidas de linguagem no fim do primeiro ano (onda 2) e no fim do segundo ano (onda 3) da pré-escola (effect sizes)

\begin{tabular}{|c|c|c|c|c|c|c|}
\hline & \multicolumn{3}{|c|}{$1^{\circ}$ ano da pré-escola } & \multicolumn{3}{|c|}{$2^{\circ}$ ano da pré-escola } \\
\hline & Modelo 1 & Modelo 2 & Modelo 3 & Modelo 1 & Modelo 2 & Modelo 3 \\
\hline Baixa escolaridade (prop. escola) & & $-0,098$ & $-0,051$ & & 0,007 & 0,034 \\
\hline Cor (prop. negros escola) & & $-0,025$ & $-0,033$ & & $-0,070$ & $-0,027$ \\
\hline Pobreza (prop. escola) & & $-0,140^{*}$ & $-0,143$ & & $-0,195^{*}$ & $-0,106$ \\
\hline Medida (onda 1) & & & $1,873^{\star * *}$ & & & \\
\hline Medida (onda 2) & & & & & & $2,306^{* * *}$ \\
\hline $\mathrm{AAC}$ & $0,390^{* * *}$ & $0,304^{\star * *}$ & $0,123^{\star}$ & $0,397^{\star * *}$ & $0,331^{\star * *}$ & $0,145^{\star *}$ \\
\hline Idade & & $0,646^{* * *}$ & $0,313^{\star * *}$ & & $0,585^{\star * *}$ & $0,249^{* * *}$ \\
\hline Sexo (menino) & & $-0,187^{\star *}$ & $-0,018$ & & $-0,221^{\star * *}$ & $-0,136^{\star *}$ \\
\hline Cor (negra) & & $-0,123^{\star *}$ & $-0,083^{*}$ & & $-0,101^{*}$ & $-0,069$ \\
\hline Baixa escolaridade & & $-0,288^{\star \star \star}$ & $-0,204^{\star \star \star}$ & & $-0,357^{\star * *}$ & $-0,205^{\star * *}$ \\
\hline Pobreza & & $-0,073$ & $-0,034$ & & $-0,146^{\star *}$ & $-0,116^{*}$ \\
\hline N Alunos & 1929 & 1772 & 1498 & 2269 & 1895 & 1575 \\
\hline N Escolas & 46 & 46 & 46 & 46 & 46 & 46 \\
\hline
\end{tabular}

Nota: ${ }^{* *} \mathrm{p}<0,001 ;{ }^{* *} \mathrm{p}<0,01 ;{ }^{*} \mathrm{p}<0,05 ;+\mathrm{p}<0,10$.Fonte: Elaboração própria.

Tabela 11. Modelos de regressão linear multinível estimando medidas de matemática no fim do primeiro ano (onda 2) e fim do segundo ano (onda 3) da pré-escola (effect sizes)

\begin{tabular}{|c|c|c|c|c|c|c|}
\hline & \multicolumn{3}{|c|}{$1^{\circ}$ ano da pré-escola } & \multicolumn{3}{|c|}{$2^{\circ}$ ano da pré-escola } \\
\hline & Modelo 1 & Modelo 2 & Modelo 3 & Modelo 1 & Modelo 2 & Modelo 3 \\
\hline $\begin{array}{l}\text { Baixa escolaridade (prop. } \\
\text { escola) }\end{array}$ & & $-0,101$ & 0,016 & & $-0,052$ & 0,002 \\
\hline Cor (prop. negros escola) & & $-0,060$ & $-0,046$ & & 0,060 & $-0,017$ \\
\hline Pobreza (prop. escola) & & $-0,057$ & $-0,080$ & & $-0,043$ & 0,001 \\
\hline Medida (onda 1) & & & $2,124^{\star * *}$ & & & \\
\hline Medida (onda 2) & & & & & & $2,414^{\star * *}$ \\
\hline $\mathrm{AAC}$ & $0,414^{* * *}$ & $0,308^{\star * *}$ & $0,152^{\star *}$ & $0,373^{\star * *}$ & $0,324^{* * *}$ & $0,126^{*}$ \\
\hline Idade & & $0,064^{* * *}$ & $0,325^{\star * *}$ & & $0,696^{* * *}$ & $0,258^{\star * *}$ \\
\hline Sexo (menino) & & $-0,064$ & 0,049 & & $0,076^{\star}$ & $0,191^{\star * *}$ \\
\hline Cor (negra) & & $-0,171^{\star \star \star}$ & $-0,071$ & & $-0,106^{\star}$ & $-0,012$ \\
\hline Baixa escolaridade & & $-0,372^{\star * *}$ & $-0,172^{\star *}$ & & $-0,313^{\star * *}$ & $-0,070$ \\
\hline Pobreza & & $-0,131^{*}$ & $-0,044$ & & $-0,152^{\star * *}$ & $-0,102^{*}$ \\
\hline N Alunos & 1929 & 1772 & 1498 & 2269 & 1895 & 1575 \\
\hline N Escolas & 46 & 46 & 46 & 46 & 46 & 46 \\
\hline
\end{tabular}

Nota: ${ }^{* * *} \mathrm{p}<0,001 ;{ }^{* *} \mathrm{p}<0,01 ;{ }^{*} \mathrm{p}<0,05 ;+\mathrm{p}<0,10$. Fonte: Elaboração própria dos autores 